\title{
SPECIFIC ASPECTS IN SEISMIC DESIGN OF TALL REINFORCED CONCRETE BUILDINGS
}

\begin{abstract}
Adrian ZĂVOIANU - PhD Student, Technical University of Civil Engineering, The Faculty of Civil, Industrial and Agricultural Buildings, e-mail: zavoianu_adrian@yahoo.com

Radu PASCU - Profesor, Phd, Technical University of Civil Engineering Bucharest, The Faculty of Civil, Industrial and Agricultural Buildings, e-mail: r_pascu@utcb.ro

Abstract: Tall buildings present some specific aspects influencing the modeling and response to seismic loads. Therefore, the design rules recommended in codes, calibrated for low and medium rise buildings, are not appropriate for design of tall buildings. Other rules are needed, and performance based design represents a viable alternative for tall buildings. In this paper a methodology for the design of tall structures is proposed and it is illustrated trough a case study for a structure with perimeter tube and interior core walls, which aims to identify the particularities regarding the design, behavior and the parameters that define the post elastic behavior at the global and local level, for this structures.
\end{abstract}

Keywords: tall buildings, nonlinear dynamic analysis, seismic design, core structures, high strength concrete

\section{Introduction}

Seismic design of tall buildings requires a relatively different approach than medium and low rise buildings. Simple extrapolation of methods and principles recommended in codes, calibrated for low rise structures is inappropriate and leads to irrational solutions from both the economic and architectural point of view. In this paper a methodology is proposed for seismic design of a tall reinforced concrete building illustrated by a case study for a structure with perimeter tube and interior core walls. This case study aims to identify the particularities regarding the design and behavior for this type of structures and also to present possible difficulties encountered in the design process. The behavior in the inelastic range represents a central concept in current buildings design philosophy. Therefore primarily the parameters that define the postelastic behavior at the global and local level will be monitored by performing nonlinear dynamic analysis for the chosen structure. It is also intended to control the cinematic plastic hinge mechanism based on the capacity design method and to provide enough resistance and ductility for the central core walls and the exterior rigid frames.

In the last decades the seismic design of tall reinforced concrete buildings has undergone an extensive development in countries like the United States, China, Japan and the United Arab Emirates. In the U.S.A a few important research projects were conducted by the Pacific Earthquake Engineering Research [1] in association with Berkeley University of California. Therefore design guidelines were developed for tall buildings that contain recommendations regarding overall conformation, design methods, seismic actions modelling and acceptance criteria for reinforced concrete tall buildings. Another set of guidelines were elaborated by the Applied Techonlogy Council (ATC) in collaboration with the Pacific Earthquake Research Center [2], [3]. This papers contain recommendation regarding the numerical modelling of tall structures (reinforced concrete elements plasticity, viscous damping, $\mathrm{P}-\Delta$ effects)

Besides the large research projects, a growing interest regarding the modelling and seismic design of tall reinforced buildings is found in world wide academic areas. These studies are usually ilustrated through case studies using the finite elemet method analysis for modelling 
nonlinear behaviour of tall reinforced concrete structures [4] or seismic peformance assessments for hybrid central core - perimetral rigid frame structures [5].

Tall buildings are complex dynamic systems and seismic design requires the use of advanced analysis methods such as nonlinear response history analysis (NRHA). In the Journal „The Structural Design of Tall and Special Buildings numerous articles " are presented about the conditions for the use of this method [6], [7], [8] in case of tall buildings. In this journal issues about seismic input, number and types of accelereograms considered and the soil - structure interaction are also presented [9].

\section{Numeric model description}

\subsection{Structure description and preliminary design}

For the numeric experiment, was chosen a structure with a two way symmetric floor plan (45x $45 \mathrm{~m})$, a total height of 56 story $(196 \mathrm{~m})$ and a story height of $3,5 \mathrm{~m}$, resulting a height to length ratio with a value of 4,4 . The structural system used is the perimeter tube and interior core walls with a square core wall $(12 \times 12 \mathrm{~m})$ and closely spaced rigid frames with a beam span of $3 \mathrm{~m}$. Between the central core and the perimetral frames, gravitational frames are placed. In figure $1 \mathrm{a}$ typical floor plan is presented and in figure 2 an axonometric view of the building is shown. Materials used are S 500 class C for reinforcement steel and C60/75 for concrete. In the preliminary design stage, the principles of the capacity design method and the rules imposed in the latest Romanian seismic codes are respected (P100-1/2013 [10], CR2-1-1.1:2013 [11]). Moreover, at this stage a seismic force reduction factor of 4 was used. Elemet sections and reinforcement ratios obtained by using the modal spectral method are presented in tables 1,2 and 3 .

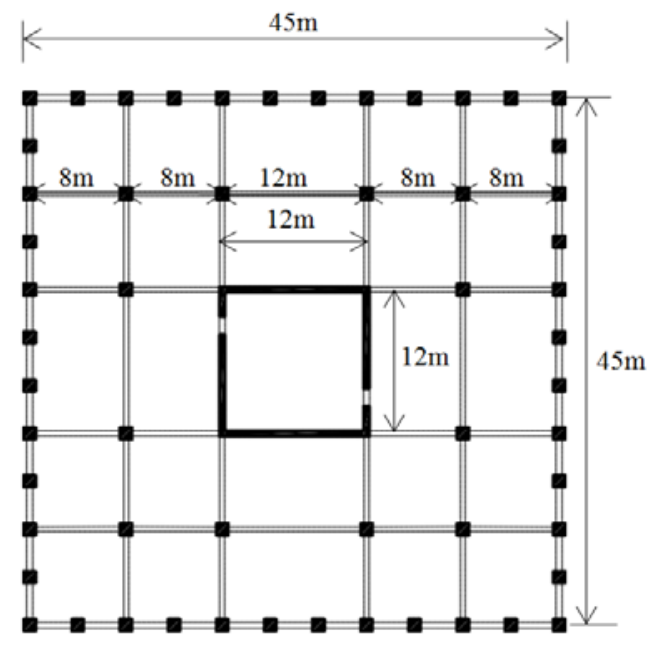

Fig. 1 - Typical floor plane for chosen structure

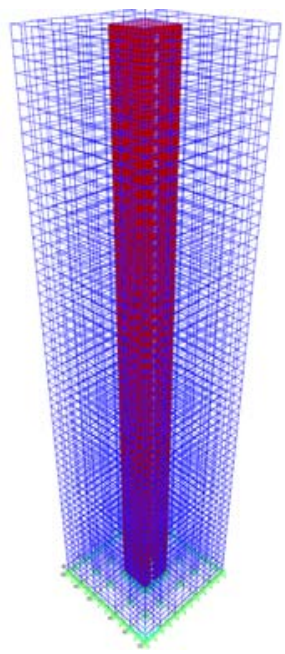

Fig.2 - Axonometric view

Table 1

Columns sections and reinforcement ratios

\begin{tabular}{|c|c|c|c|c|c|}
\hline \multirow{2}{*}{ Element } & STORY & \multirow{2}{*}{$\mathrm{b}[\mathrm{cm}]$} & \multirow{2}{*}{$\mathrm{h}[\mathrm{cm}]$} & \multicolumn{2}{|c|}{ Effective reinforcement ratios } \\
\cline { 5 - 6 } & & & & Long. $(\%)$ & Transv. $(\%)$ \\
\hline Columns & Ground - Story 55 & 100 & 100 & 1.18 & 1.13 \\
\hline
\end{tabular}

Beams sections and reinforcement ratios

\begin{tabular}{|c|l|c|c|c|c|}
\hline \multirow{2}{*}{ Element } & \multicolumn{1}{|c|}{ STORY } & \multirow{2}{*}[\mathrm{cm}]{} & $\mathrm{h}[\mathrm{cm}]$ & \multicolumn{2}{|c|}{ Effective reinforcement ratios } \\
\cline { 5 - 6 } & & & & Sup. $(\%)$ & Inf.(\%) \\
\hline \multirow{2}{*}{$\begin{array}{c}\text { Perimetral } \\
\text { frames beams }\end{array}$} & Ground - Story10 & 50 & 130 & 0.51 & 0.51 \\
\cline { 2 - 6 } & Story 11- Story 35 & 50 & 130 & 0.58 & 0.58 \\
\cline { 2 - 6 } & Story 36 - Story 55 & 50 & 130 & 0.51 & 0.51 \\
\hline $\begin{array}{c}\text { Interior frames } \\
\text { beams }\end{array}$ & Ground - Story 55 & 40 & 70 & 1.13 & 0.63 \\
\cline { 2 - 6 } & Ground - Story 55 & 40 & 100 & 0.63 & 0.58 \\
\hline
\end{tabular}


Central core wall sections and reinforcement ratios

\begin{tabular}{|c|c|c|c|c|}
\hline \multirow{2}{*}{ Element } & \multirow{2}{*}{ STORY } & \multirow{2}{*}{$\mathrm{b}[\mathrm{cm}]$} & \multicolumn{2}{|c|}{ Effective reinforcement ratios } \\
\cline { 4 - 5 } & & & Extrem. (\%) & Central (\%) \\
\hline Walls & Ground - Story 55 & 50 & 1.21 & 0.31 \\
\hline
\end{tabular}

Modal information

\begin{tabular}{|c|c|c|l|}
\hline Mode & Periods [s] & $\begin{array}{c}\text { Modal } \\
\text { mass [\%] }\end{array}$ & \multicolumn{1}{|c|}{ Direction } \\
\hline 1 & 4,7 & 68,1 & Translation y \\
\hline 2 & 4,7 & 68,0 & Translation x \\
\hline 3 & 2,6 & 0,0 & Torsion \\
\hline 4 & 1,3 & 14,0 & Translation y \\
\hline 5 & 1,3 & 13,9 & Translation x \\
\hline 6 & 0,9 & 0,0 & Torsion \\
\hline 7 & 0,6 & 5,4 & Translation y \\
\hline 8 & 0,6 & 5,4 & Translation x \\
\hline
\end{tabular}

\subsection{Nonlinearmodel description}

For the evaluation of element capacity expected properties of materials was considered. Moreover, for concrete confinement in column and wall extremities the model proposed by Cusson and Paultre [12] was used, being model calibrated for high strength concrete. For the reinforcement steel, the bilinear model without consolidation was considered. Inelastic behavior of beams and columns was defined using Clough model, with an isotropic hysteretic model. For central core walls, inelasticity was considered using the "sandwich model" by dividing the wall section in 5 layers ( 2 for concrete cover, 2 for longitudinal reinforcement and 1 for concrete core) without the explicit definition of horizontal reinforcement which is supposed to behave elastic.

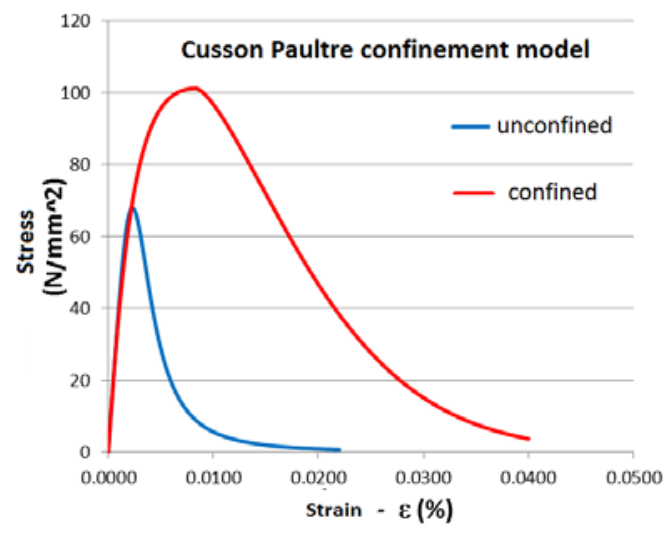

Fig. 4 - Cusson-Paultre confinement model

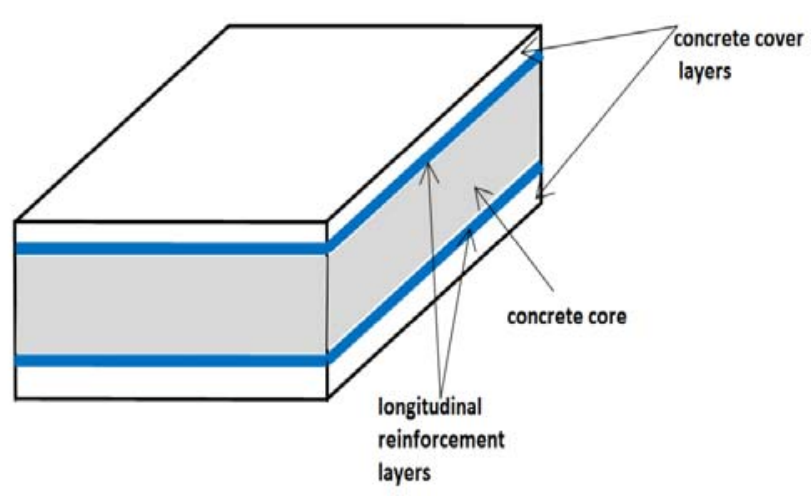

Fig.5 - Multilayer model

For the construction of the damping matrix, the Rayleigh model was used (value of 5\% for viscous damping coefficient for modes 1 and 3) and for the numerical integration the HubertHuges-Taylor method. Seismic input is represented by 5 bidirectional synthetic accelerograms compatible with the elastic design spectrum defined in P100-1/2006 for $\mathbf{T}_{\mathbf{c}}=1,6 \mathrm{~s}$ : Bucharest 4 march 1977, Kobe Tak 95, Northrige 95, Kobe Fuk 95 and Kozani 95.

\subsection{Dynamic analysis results}

Given the fact that 5 accelerograms were used, in most guidelines consideration of the maxim response is recommended (FEMA 356 [13], Eurocod 8 [14]). The nonlinear dynamic analysis emphasizes the initiation of the cinematic mechanism only for accelerograms Kobe Tak 95, 
Northrige 95 and Kozani 95. In this subchapter, the response history is presented for significant response quantities resulted from nonlinear analysis and comparisons with results from response spectrum analysis. In figure 5 the displacement of the elastic system is multiplied with q while other response quantities have resulted from models with reduced lateral forces.
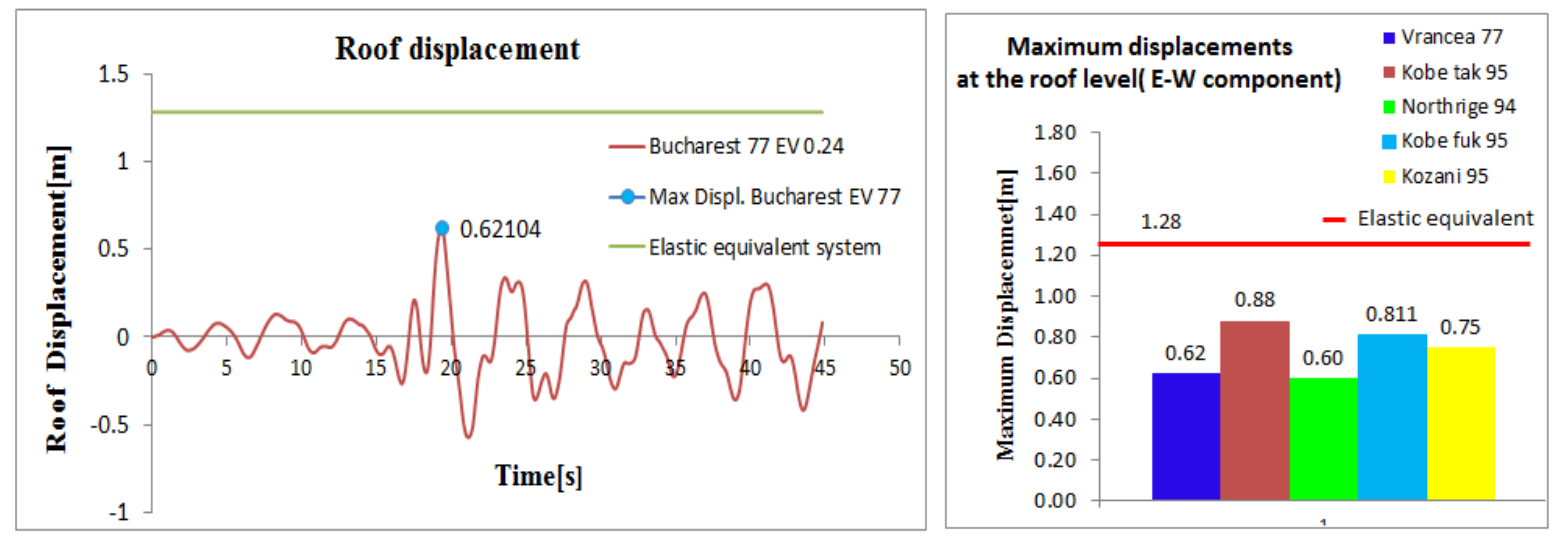

Fig. 5 - Roof displacement response history for Bucharest $77 \mathrm{E}-\mathrm{W}$ accelerogram and comparisions of maximum displacement for all 5 accelerograms considered
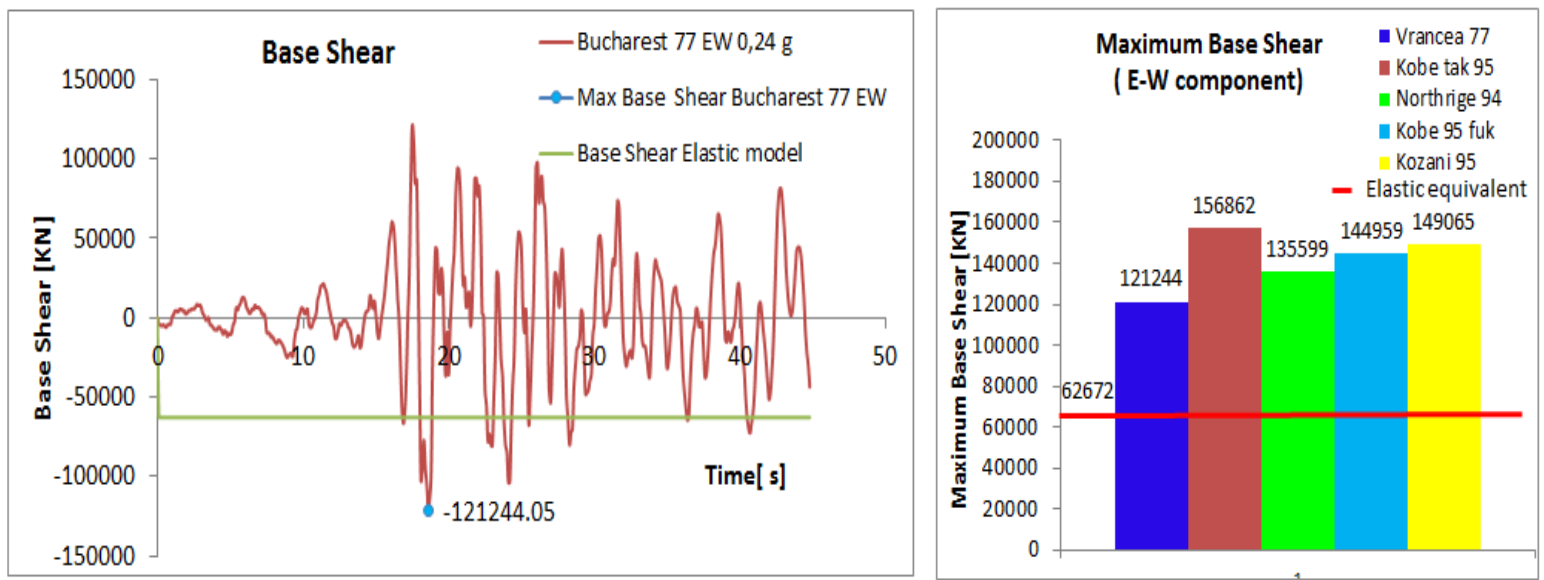

Fig. 6 - Shear Base response history for Bucharest 77 E-W accelerogram and comparisions of maximum base shear for all 5 accelerograms considered

Shear forces in perimeter frame beams resulted from nonlinear dynamic analysis have values between 1300-1500 KN, less than capacity corresponding to reinforcement determined from preliminary design (2032 $\mathrm{KN}$ for a transversal reinforcement ratio of $0,63 \%$ ).

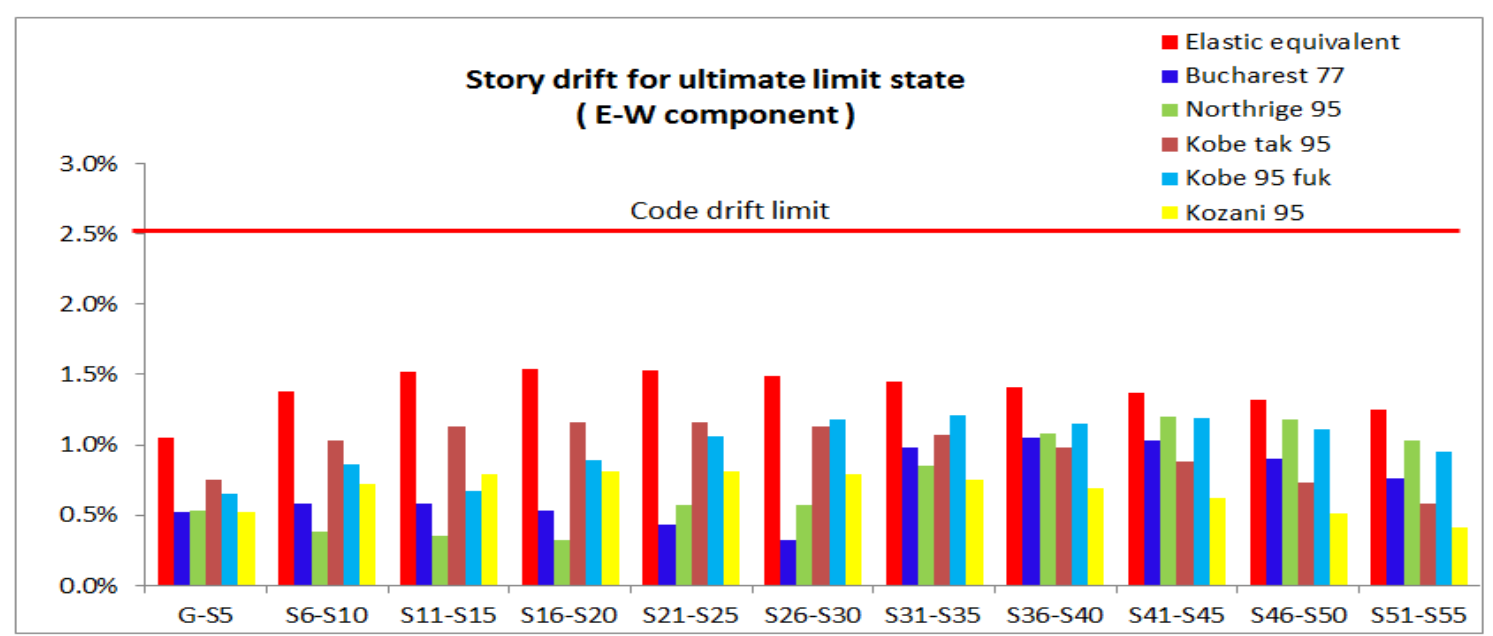

Fig. 7 - Maximum story drifts for all 5 dynamic analyis cases 
Plastic hige rotation

\begin{tabular}{|c|l|c|c|}
\hline \multirow{4}{*}{ Element } & Accelerograms & $\theta$ pl ef max & $\theta$ pl adm \\
\hline \multirow{4}{*}{ BEAMS } & Vrancea 77 & 0,0030 & 0,0135 \\
\cline { 2 - 4 } & Kobe Fuk 95 & 0,0025 & 0,0143 \\
\cline { 2 - 4 } & Kobe Tak 95 & 0,0047 & 0,0136 \\
\cline { 2 - 4 } & Kozani 95 & 0,0029 & 0,0148 \\
\cline { 2 - 4 } & Northrige & 0,0054 & 0,0180 \\
\hline \multirow{5}{*}{ COLUMS } & Vrancea 77 & 0 & 0,0093 \\
\cline { 2 - 4 } & Kobe Fuk 95 & 0 & 0,0091 \\
\cline { 2 - 4 } & Kobe Tak 95 & 0,0018 & 0,0096 \\
\cline { 2 - 4 } & Kozani 95 & 0,0017 & 0,0082 \\
\cline { 2 - 4 } & Northrige & 0,0017 & 0,0073 \\
\hline \multirow{5}{*}{ WALLS } & Vrancea 77 & 0,0008 & 0,0067 \\
\cline { 2 - 4 } & Kobe Fuk 95 & 0,0010 & 0,0075 \\
\cline { 2 - 4 } & Kobe Tak 95 & 0,0013 & 0,0082 \\
\cline { 2 - 4 } & Kozani 95 & 0,0009 & 0,0081 \\
\cline { 2 - 4 } & Northrige & 0,0008 & 0,0087 \\
\hline
\end{tabular}

Admissible plastic hinge rotations were determined using the analytical model from Eurocode 8 part III [14] with equation:

$$
\theta_{p l}^{u m}=\frac{1}{\gamma_{e l}}\left(\phi_{u}-\phi_{y}\right) L_{p l}\left(1-0,5 \frac{L_{p l}}{L_{V}}\right)
$$
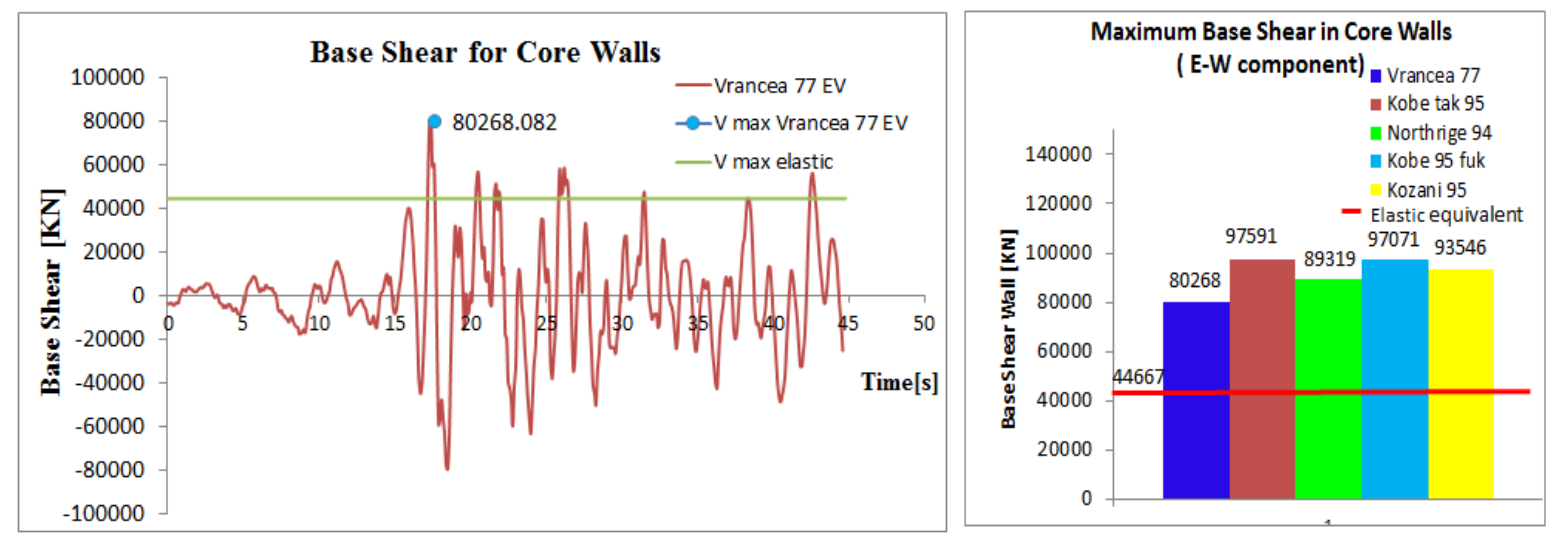

Fig. 8 - Base Shear in core walls response history for Bucharest 77 E-W accelerogram and comparisons of maximum base shear in walls for all 5 accelerograms considered
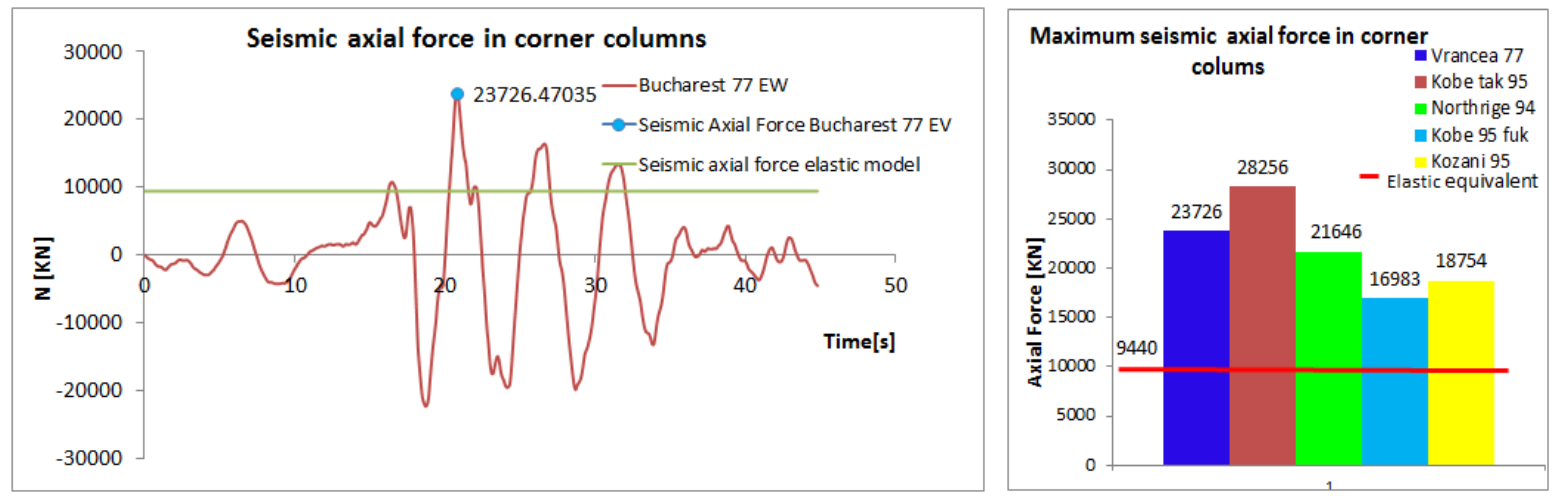

Fig. 9 - Response history for seismic base axial forces in corner columns and comparisons of the maximum values for all 5 accelerograms 


\section{Conclusions}

Results of nonlinear dynamic analysis for the chosen structure show that values of story drifts, plastic hinge rotations and shear forces are lower than the acceptable limits and theoretically we could decrease the quantity of reinforcement. But we must take into consideration that design resistance was used in the preliminary design of the elements and the safety limits should be evaluated more exactly. Also, the plastic hinge rotation limits for the structural elements are low due to the use of high strength concrete and reduced slenderness of the elements.

The reduction of the element sections is difficult because it is obtained by limiting axial and shear stress. We also need to ensure effectiveness of the perimetral tube, thing that requires the use of very stiff elements.

Another aspect revealed by the nonlinear dynamic analysis is represented by large amplitudes of tension and compression axial forces in the exterior frame corner columns. This fact is emphasized by the shear lag effect, a phenomenon distinctive for tubular structures. Therefore in the corner columns the occurrence of plastic hinge rotation for all floors is observed. These drawbacks can be limited by using beams with high stiffness in perimetral tube. We can also significantly improve the behavior of this structures by using additional systems composed from the perimetral wall or truss belts connected by very high beams with central core, referred to in literature as "outrigger and belt" [15], [16].

\section{References}

[1] TBI Guidelines Working Group. (2010). Guidelines for performance-based seismic design of tall buildings. Berkeley: University of California (PEER Report No. 2010/05).

[2] Applied Technology Council. (2010). Modeling and acceptance criteria for seismic design and analysis of tall buildings. Redwood City: Applied Technology Council (PEER/ATC Report No. 72-1).

[3] Applied Technology Council. (2010). Proceedings of workshop on tall building seismic design and analysis issues. Redwood City: Applied Technology Council (ATC Report No. 72).

[4] Lin XC, Lu XZ, Miao ZW, Ye LP, Yu YQ, Shen L. (2009). Finite element analysis and engineering application of RC core-tube structures based on the multi-layer shell elements. China Civil Engineering Journal, 42(3), 49-54. Retrived 21 October 2013 from: http://www.oriprobe.com/journals/tmgcxb.html.

[5] Miao ZW, Ye LP, Wu YH, Ma QL, Lou Y, Lu XZ. (2009). Seismic performances and failure mode analysis of hybrid frame-core tube structures. Building Structure, 39(04), 1-6.

[6] Powell, G. (2006). Nonlinear dynamic analysis capabilities and limitation. The Structural Design of Tall and Special Buildings, 15, 547-552. DOI: 10.1002/tal.381.

[7] Moehle, J.P. (2005). Nonlinear analysis of performance-based earthquake engineering. The Structural design of Tall and Special Buildings, 14, 385-400. DOI: 10.1002/tal.334

[8] Moehle, J.P. (2007). The tall buildings initiative for alternative seismic design. The Structural Design of Tall and Special Buildings, 16, 559-567. DOI: 10.1002/tal.435.

[9] Stewart P., Tileylioglu S. (2007). Input ground motions for tall buildings with subterranean levels. The Structural Design of Tall and Special Buildings, 16, 543-557. DOI: 10.1002/tal.429.

[10] Ministerul Dezvoltării Regionale şi Adminstraţiei Publice. (2013). Cod de proiectare seismică, Partea I, Prevederi de proiectare pentru clădiri, Indicativ P100-1/2013. Bucureşti: Monitorul Oficial al României.

[11] Ministerul Dezvoltării Regionale şi Adminstraţiei Publice. (2013). Cod de proiectare a construcţiilor cu pereţi structurali de beton armat, Indicativ CR2-1-1.1:2013. Bucureşti: Monitorul Oficial al României.

[12] Cusson D., Paultre P. (1994). High-strength concrete columns confined by rectangular ties. ASCE Journal of Structural Engineering, 120(3), 783-804. DOI:10.1061/(ASCE)0733-9445(1994)120:3(783).

[13] FEMA. (2000). Prestandard and Commentary for the Seismic Rehabilitation of Buildings.Washington, D.C: Federal Emergency Management Agency.

[14] European Committee for Standardization. (2006). Eurocode 8: Design of structures for earthquake resistance Part 3: Strengthening and repair of buildings. Brussels.

[15] Taranath, S.T. (2010). Reinforced concrete design of tall buildings. New York: CRC Press Taylor \& Francis Group.

[16] Taranath, S.T. (1997). Wind and Earthquake resistant buildings structural analysis and design. New York: Marcel Dekker. 